\title{
Geomagnetic Mapping of the Macaé Region, Brazil
}

\author{
Igor Rodrigues Salvador de Menezes', Júllia Medeiros Figueiredo', \\ Davi Antônio Ferreira Velloso', Maria Eduarda da Silva Bento1, \\ Iuri de Azevedo Lima1, Hans Schmidt Santos ${ }^{2}$ \\ ${ }^{1}$ Instituto Nossa Senhora da Glória (INSG), Macaé, Brazil \\ ${ }^{2}$ Faculdade Salesiana Maria Auxiliadora (FSMA), Macaé, Brazil \\ Email: hans.schmidt@live.com
}

How to cite this paper: de Menezes, I.R.S., Figueiredo, J.M., Velloso, D.A.F., da Silva Bento, M.E., de Azevedo Lima, I. and Santos, H.S. (2019) Geomagnetic Mapping of the Macaé Region, Brazil. Open Access Library Journal, 6: e5593.

https://doi.org/10.4236/oalib.1105593

Received: July 9, 2019

Accepted: July 27, 2019

Published: July 30, 2019

Copyright $\odot 2019$ by author(s) and Open Access Library Inc.

This work is licensed under the Creative Commons Attribution International License (CC BY 4.0).

http://creativecommons.org/licenses/by/4.0/

\begin{abstract}
This work presents the geomagnetic characterization of the municipality of Macaé, Brazil. Data from IGRF12 (twelfth edition of International Geomagnetic Reference Field) were used. Through the data collected in a regular grid of 0.1 degrees of the components, north, east and vertical were generated maps of components, inclination, declination, horizontal component and geomagnetic total field. The results showed important relative variations of these magnitudes, such as the magnetic declination that varied around 0.2 degrees along the area of the municipality, which is a considerable value and capable of causing significant changes in directions by compass in the studied region.
\end{abstract}

\section{Subject Areas}

Environmental Sciences, Geology, Geomorphology, Geophysics

\section{Keywords}

Geomagnetic Field, IGRF, Macaé

\section{Introduction}

Magnetism is the name given to studies of the phenomena associated with magnets. The first record on magnetic phenomena happened in the city of Magnesia, from which originated the word "magnetic" in ancient Greece. The earliest studies in this area were made in the sixth century BC by Tales of Miletus, who observed that certain stones, now called as magnetite, were characterized by their natural ability to be attracted to other stones and iron. In the sixth century, the 
Chinese already made magnets and applied them to the compass, but only in the thirteenth century that studies about magnetism were resumed with observations and experiments guided by Europeans [1] [2].

Pierre Pelerin as early as 1269 discovered through various experiments some basic features concerning the magnets, such as its extremities, which he called north and south, and that the compass needle pointed approximately to the geographic north of the Earth. However, magnetism really benefited human development when Shen Kua added the magnetic needle to navigation by taking it as an astronomical guide [3].

Thus, the study of magnetism over the centuries has enabled the invention and improvement of instruments such as the electric motor, loudspeakers, magnetic cards, telecommunication apparatus and others, besides that, these forces act on generators and transformers in hydroelectric plants, providing electricity to home and industries [4].

The International Geomagnetic Reference Field (IGRF) is a standard mathematical description for the whole world of the large-scale structure of Earth's main magnetic field and its secular variation. Because the IGRF model covers a significant amount of time, it is very useful for interpreting historical data. The model is updated at 5-year intervals, reflecting the most accurate measurements available at that time [5]. The current 12th edition of the IGRF model was launched in 2015 and is valid from 1900 to 2020.

Macaé is a Brazilian city in the state of Rio de Janeiro, Brazil, located 180 kilometers northeast of the state capital. The city is known as the national capital of oil and is nicknamed "Little Princess of the Atlantic", with a total area of 1216 square kilometers, corresponding to $12.5 \%$ of the area of the northern region of Rio de Janeiro [6].

The city is divided into six districts-Headquarters, Cachoeiros de Macaé, Córrego do Ouro, Glicério, Frade and Sana. The population was 251,631 inhabitants in 2018 [7]. The Macaé city is currently located in a planet region that has the lowest values of magnetic field intensity, being this region called South Atlantic Anomaly (SAA). In addition, the region is bathed by the Atlantic Ocean and has navigable rivers such as the Macaé, Sana and São Pedro rivers, thus being an interesting region for a geomagnetic study due to the navigation and the presence of the SAA.

The research scheme was developed from the following steps: data collection of the components of field IGRF-12; calculation of the magnetic inclination and declination; calculation of the magnetic total field and horizontal component; data interpolation and mapping; analysis of results. Thus, Section 2 of this paper describes the general characteristics of Macaé as location, topography and land use. Section 3 addresses the characteristics of the Earth's magnetic field. Section 4 discusses the geomagnetic field model used in this work. Section 5 describes the data processing and discusses the results. Finally, Section 6 brings together the main final considerations. 


\section{Macaé Characteristics}

The municipality of Macaé is part of the North Fluminense region, which comprises the following municipalities: Campos dos Goytacazes, Carapebus, Cardoso Moreira, Conceição de Macabu, Macaé, Quissamã, São Fidelis, São Francisco de Itabapoana and São João da Barra. They are neighboring municipalities: Rio das Ostras, Nova Friburgo, Conceição de Macabu, Carapebus, Trajano de Moraes and Casimiro de Abreu. The following districts stand out: Sana, Bicuda Grande, Bicuda Pequena, Cachoeiros de Macaé, Glicério, Areia Branca, Córrego do Ouro and Barra de Macaé (Figure 1) [8].

The city is well known for its beaches and for having a large amount of oil in its waters. Because its economy is based on oil exploration, Macaé is known as the "National Capital of Oil". The name of the municipality is a reference to the Macaé River that crosses good extension of the municipality. The climate is hot and humid for most of the year, with temperatures varying between $23^{\circ} \mathrm{C}$ and $38^{\circ} \mathrm{C}$. This large amplitude is caused by the exchange of winds between the coast and the mountain that are relatively close [6].

The relief of the municipality is considered as undulating with narrow valleys. The altitude varies from the sea level up to a little over $1 \mathrm{~km}$ in altitude according to the map made using data from the V19.1 TOPEX topography model developed by the Oceanography Institute of the San Diego University (Figure 2) [10].

The plain sector of Macaé is dominated by pastures and also by the monoculture of sugar cane. In the vicinity of the sea and in the lagoons, it can still be found some bushes and underwoods. In the mountainous region to the west of the municipality, the Atlantic Forest can be found in some sectors (Figure 3) [11].

Due to its oil resources, Macaé has grown in population and economy in recent years, making it a good place for routes of ships and other transportation. Thus, geomagnetic mapping can aid in navigation and transport systems like these.



Figure 1. Municipality of Macaé [9]. 


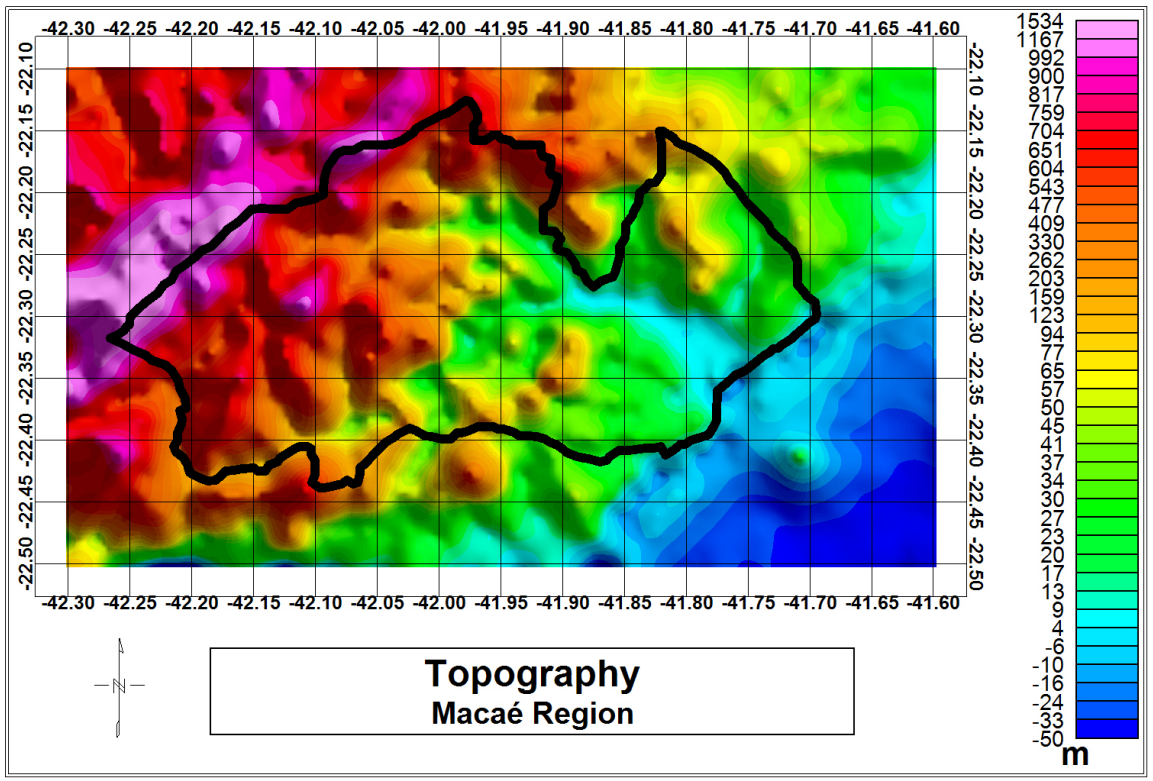

Figure 2. Topographic map of Macaé made from TOPEX V19.1 model data [9].



Figure 3. Satellite view of the municipality of Macaé [11].

\section{Earth's Magnetic Field}

The first modern scientific work on the Earth's magnetic field was published in 1600 by William Gilbert, where he argues that planet Earth is like a great magnet. Over the years this idea was improved, it was proven in 1690 that the earth's magnetic field changes over time, and in 1835 a method was created to measure the magnetic field strength [12].

In addition, it was concluded that the Earth's magnetic field manifested a variation in amplitude and direction over the years, which was termed "secular variation" and faster variations of this field were related to atmospheric phenomena such as auroras [13].

The magnetic field can be represented by lines of magnetic field, which emerge from the magnetic north (near the geographical south) and converge 
towards the magnetic south (near the geographic north). This describes the pattern of directions of the magnetic field, where in the closest lines the intensity of the magnetic field is greater, and in the lines more spaced the intensity of the magnetic field is smaller. Thus, the magnetic field is stronger at the poles than at any other location on Earth (Figure 4) [14].

Our planet is surrounded by a magnetic field and this phenomenon is revealed, for example, by a needle of a compass that points approximately to the north. According to modern ideas, when at a given point a measurement of the Earth's magnetic field is carried out, the measured value is the result of superposition of contributions having different origins such as fluid nucleus, crust and interaction of the Earth with the Sun (Figure 5) [5] [14].

Secular variation is a progressive temporal change in all geomagnetic elements, being a consequence of the patterns of circulation within the nucleus,

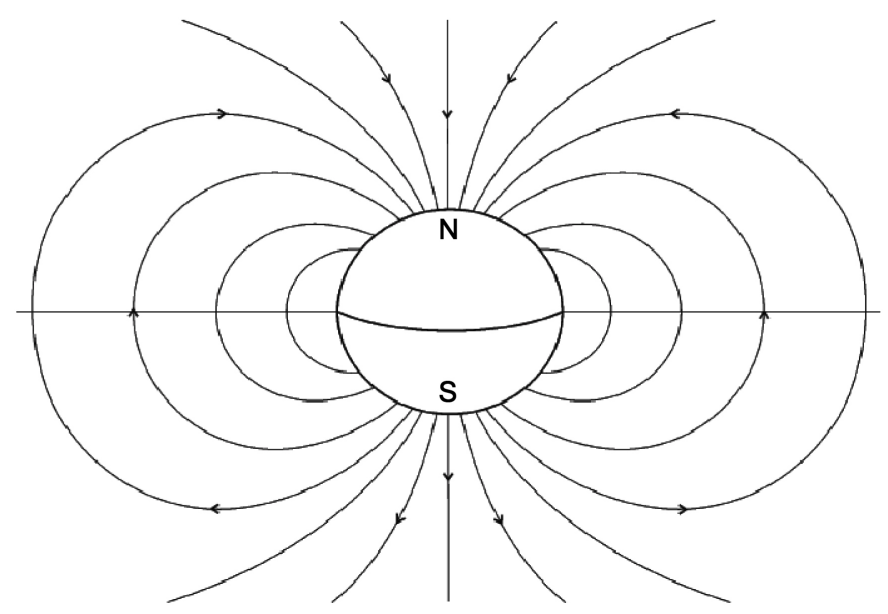

Figure 4. Idealized view of the Earth's magnetic field lines. $\mathrm{N}$ and $\mathrm{S}$ are the ideal location of the two magnetic poles [14].

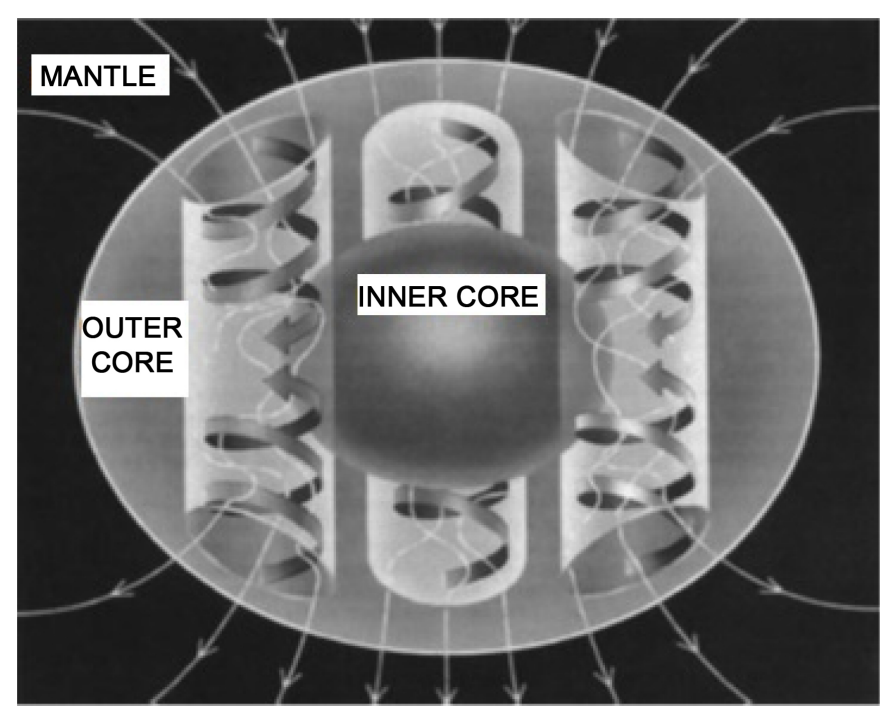

Figure 5. A possible configuration for the fluid flow and the field inside the nucleus [5]. 
because they are not fixed and change slowly with time. Such a variation is predictable, a well-known example is the gradual rotation of the magnetic pole around the geographic north pole [13].

The Ionospheric Dynamo is produced by currents induced by both the outer core and the solar and lunar activity. These variations are due mainly to the activities of the solar wind on the planet. They are relatively inferior, compared to the main field, and can be periodic (daily) or irregular [15].

Other magnetic effects of external origin make the magnetic field vary daily, these variations are called diurnal variations. Under normal conditions, diurnal variations have an amplitude of about 20 to $80 \mathrm{nT}$, having greater amplitude in the polar regions. This variation is a result of the magnetic field induced by the flow of charged particles that settle from the ionosphere towards the magnetic poles, circulation patterns and diurnal variations vary according to the effects of the tide, the sun and the moon [13].

Thus, according Lanza and Meloni (2006) [14], the geomagnetic field has three main sources:

- The main field, generated in the Earth's fluid nucleus by a mechanism called the "dynamo theory" produced by the circulation of charged particles in convective cells coupled to the fluid outside of the Earth's core;

- The crustal field, generated by magnetized rocks in the crust of the Earth (lithosphere);

- The external field, produced by electric currents flowing in the ionosphere and magnetosphere (layers of the Earth's atmosphere), due to the interaction of the Earth's magnetic field with electromagnetic radiation and solar winds.

At any point on the Earth's surface, a freely suspended magnetic needle will recognize a position in space toward the geomagnetic field, making an angle to the vertical and geographic north. To describe the magnetic field vector, descriptors known as geomagnetic components are used. The total field vector $(B)$ has a vertical component $(Z)$ and a horizontal component $(H)$ in the magnetic north direction. The dip of $\mathrm{B}$ is the inclination $(I)$ of the field, and the horizontal angle between the geographic and magnetic north is the declination $(D)$ (Figure 6) [16].

According Blakely (1995) [16], the total field vector $(B)$ alternates in intensity from about 25,000 $\mathrm{nT}$ in the equatorial regions to about 70,000 $\mathrm{nT}$ at the poles. If the magnetic field is represented in Figure 6, the equations below show the relationship between the components of the magnetic field:

$$
\begin{gathered}
I=\arctan \frac{B_{z}}{\sqrt{B_{x}^{2}+B_{y}^{2}}} \\
D=\operatorname{arcsen} \frac{B_{y}}{\sqrt{B_{x}^{2}+B_{y}^{2}}} \\
H=\sqrt{B_{x}^{2}+B_{y}^{2}} \\
T=\sqrt{B_{x}^{2}+B_{y}^{2}+B_{z}^{2}}
\end{gathered}
$$




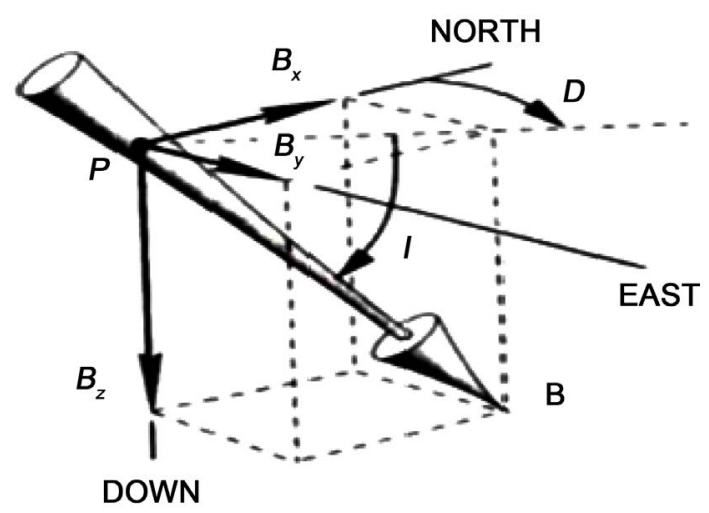

Figure 6. Representation of the magnetic field and its projected components [16].

At where:

- Magnetic inclination (I),

- Magnetic declination $(D)$,

- X Component $\left(B_{X}\right)$,

- Y Component $\left(B_{y}\right)$,

- Z Component $\left(B_{z}\right)$,

- Horizontal Component $(H)$,

- Total field $(B)$.

If the compass needle is allowed to swing freely, it will be parallel to the Earth's surface in areas near the Equator but will be positioned vertically at points near the North and South poles. In the northern hemisphere, the magnetic field generally points downward and becomes vertical at the magnetic north pole, which represents the inclination of $90^{\circ}$, on the other hand, in the southern hemisphere, the pointing is generally upward, and the south magnetic pole has inclination of $-90^{\circ}$. The zero inclination line approaches the geographic equator. This location is known as the magnetic equator [2] [13].

It is estimated that about $90 \%$ of the Earth's field can be represented by the field of a theoretical magnetic dipole in the center of the Earth, inclined about $11.50^{\circ}$ to the axis of rotation. Thus, the magnetic inclination can be calculated as the vertical angle between vector $B$ and the horizontal plane [13].

The North shown by the compass is the Magnetic North, not the Geographic North. The difference is usually not large enough to change our daily lives, but anyone who works with field research, cartography, aerial photography, and topography needs to know the difference between the two values. The angle between the directions of Geographic North and Magnetic North is called magnetic declination. It varies from place to place on Earth and varies also over time. The magnetic declination is defined as the azimuth of the magnetic meridian, positive for East and negative for West [13] [17].

\section{International Geomagnetic Reference Field (IGRF)}

The IGRF is a spherical model used internationally to the Geomagnetic Field 
whose sources are in the Earth's core. It is updated every five years, according to the International Association of Geomagnetism and Aeronomy (IAGA). The IGRF emerged after discussions by the World Magnetic Survey (WMS). The WMS was a set of researches on the Magnetic Field by the earth, the seas, the skies and other means, between the years of 1957 and 1969 [5].

At a meeting in late 1960, an IAGA committee recommended that a spherical harmonic analysis must be done using the WMS results, and this proposal was accepted. After eight years of discussion the IGRF was built, and the following year, 1969, the IGRF began to be used as an international model [5].

The IGRF comes from an international collaboration based on the cooperation of institutes responsible for the collection and publication of magnetic field data. The model incorporates data from the permanent observatories and is based on the expansion of spherical harmonics. The magnetic moment of this fictitious geocentric dipole can be calculated from the observed field. If this dipole field is subtracted from the observed magnetic field, the residual field can then be approximated by the effects of a smaller, second dipole. The method can be redone, with a decreasing adjustment until the observed geomagnetic field is emulated according to the degree of precision required [13].

Thus, the effects of each dummy dipole contribute to a function known as a harmonic, and the technique of successive approximations of the observed field is termed as spherical harmonic analysis, the equivalent of Fourier analysis in spherical polar coordinates. This method was used to calculate the International Geomagnetic Field Reference (IGRF) formula, which determines the undisturbed theoretical magnetic field at any point on the Earth's surface [13].

The geomagnetic field changes over time, however, the IGRF is a mathematical equation. As international agreements are not easily established in short time intervals, new IGRF models are adapted to 5 year intervals, with the intention of representing the geomagnetic field within that time interval. The IGRF model currently in use is the $12^{\text {th }}[16]$.

According Thébault et al. (2015) [18], the IGRF is a series of mathematical models of the internal geomagnetic field $\boldsymbol{B}(r, \theta, \varphi, t)$ and its rate of change (secular variation). On and above the Earth's surface, the magnetic field $\boldsymbol{B}$ is defined in terms of a magnetic scalar potential $V$ by $\boldsymbol{B}=-\nabla V$ and where in spherical polar co-ordinates $V$ is approximated by the finite series

$$
\begin{aligned}
& V(r, \theta, \varphi, t) \\
& =\alpha \sum_{n=1}^{N} \sum_{m=1}^{n}\left(\frac{a}{r}\right)^{n+1} \times\left[g_{n}^{m}(t) \cos (m \varphi)+H_{n}^{m}(t) \sin (m \varphi) P_{n}^{m}(\cos \theta)\right]
\end{aligned}
$$

With $r$ denoting the radial distance from the center of the Earth, $a=6371.2$ $\mathrm{km}$ being the Earth's mean reference spherical radius, $\theta$ denoting geocentric co-latitude, and $\varphi$ denoting east longitude. The functions $P_{n}^{m}(\cos \theta)$ are the Schmidt quasi-normalized associated Legendre functions of degree $n$ and order $m$. The Gauss coefficients $g_{n}^{m}, h_{n}^{m}$ are functions of time and are conventionally given in units of nanotesla (nT) [18]. 


\section{Processing and Results}

The data used in this work were collected from the IGRF-12 model for the date of February 26, 2019. Data were collected in a rectangle between -42.3 degrees and -41.6 degrees of longitude and -22.5 degrees and -22.1 degrees of latitude. The resolution of the collected data was 0.1 degree in a regular mesh. Data were processed using Oasis Montaj software from Geosoft (Figure 7).

The data of components (X, Y, Z), angles (inclination and declination) and resulting (horizontal and total) were interpolated using the Minimum Curvature Method with $1 / 4$ cells of data resolution, that is, 0.25 degrees.

The interpolation result of the components $(\mathrm{X}, \mathrm{Y}, \mathrm{Z})$ is presented by Figures 8-10, respectively.

The $\mathrm{X}$ component aligned with the magnetic north in the studied region had its values varying between $16,131 \mathrm{nT}$ and $16,323 \mathrm{nT}$, the values being increased in the direction of southeast to northwest of the municipality. Thus, there was an environmental variation of $192 \mathrm{nT}$ throughout the studied region, which is equivalent to approximately $1.2 \%$.

The Y component aligned with the magnetic east in the studied region had its values ranging from $-7033 \mathrm{nT}$ to $-6969 \mathrm{nT}$, with magnitudes increasing from southwest to northeast of the municipality. Thus, there was an environment variation of $64 \mathrm{nT}$ throughout the studied region, which is equivalent to approximately $0.9 \%$.

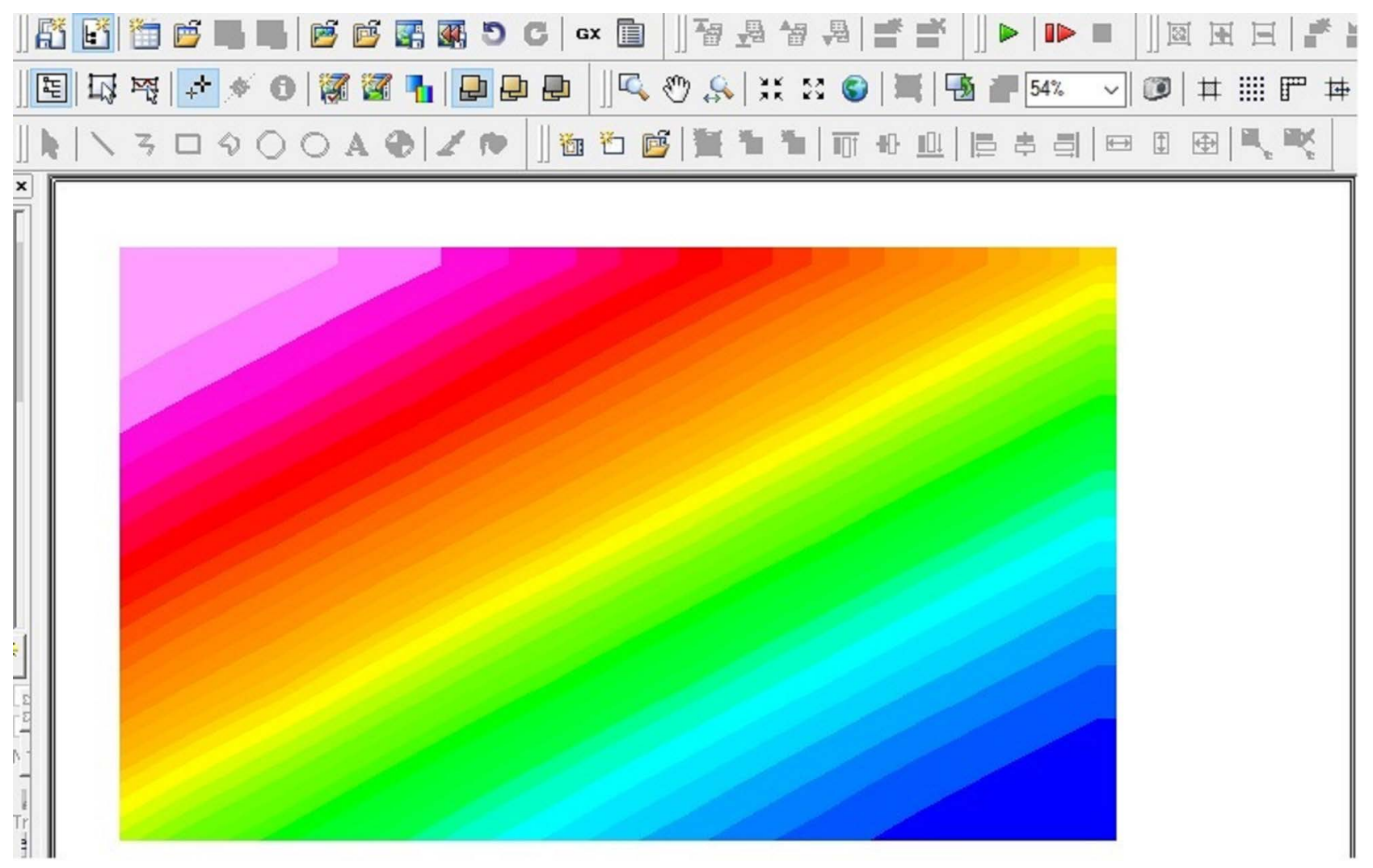

Figure 7. Oasis Montaj software working screen. 


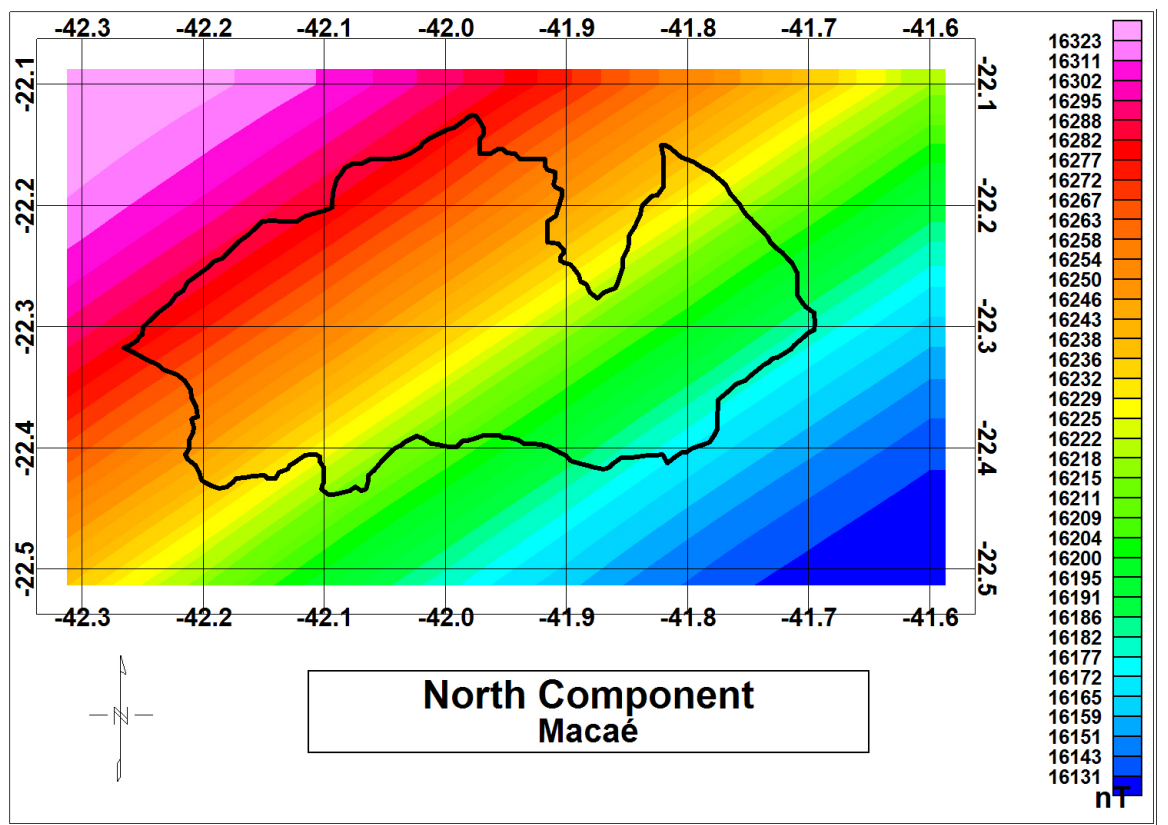

Figure 8. Component $\mathrm{X}$ of the magnetic field.



Figure 9. Component $\mathrm{Y}$ of the magnetic field.

The $\mathrm{Z}$ component aligned with the vertical in the studied region had its values ranging from $-15,428 \mathrm{nT}$ to $-15,156 \mathrm{nT}$, with magnitudes increasing from the northwest to the southeast of the municipality. Thus, there was an environment variation of $272 \mathrm{nT}$ throughout the studied region, which is equivalent to approximately $1.8 \%$.

Through the values of the components (X, Y, Z) and of Equations (1) and (2), the values of magnetic inclination and magnetic declination can be calculated. The result of the interpolation of the angles (inclination and declination) is 


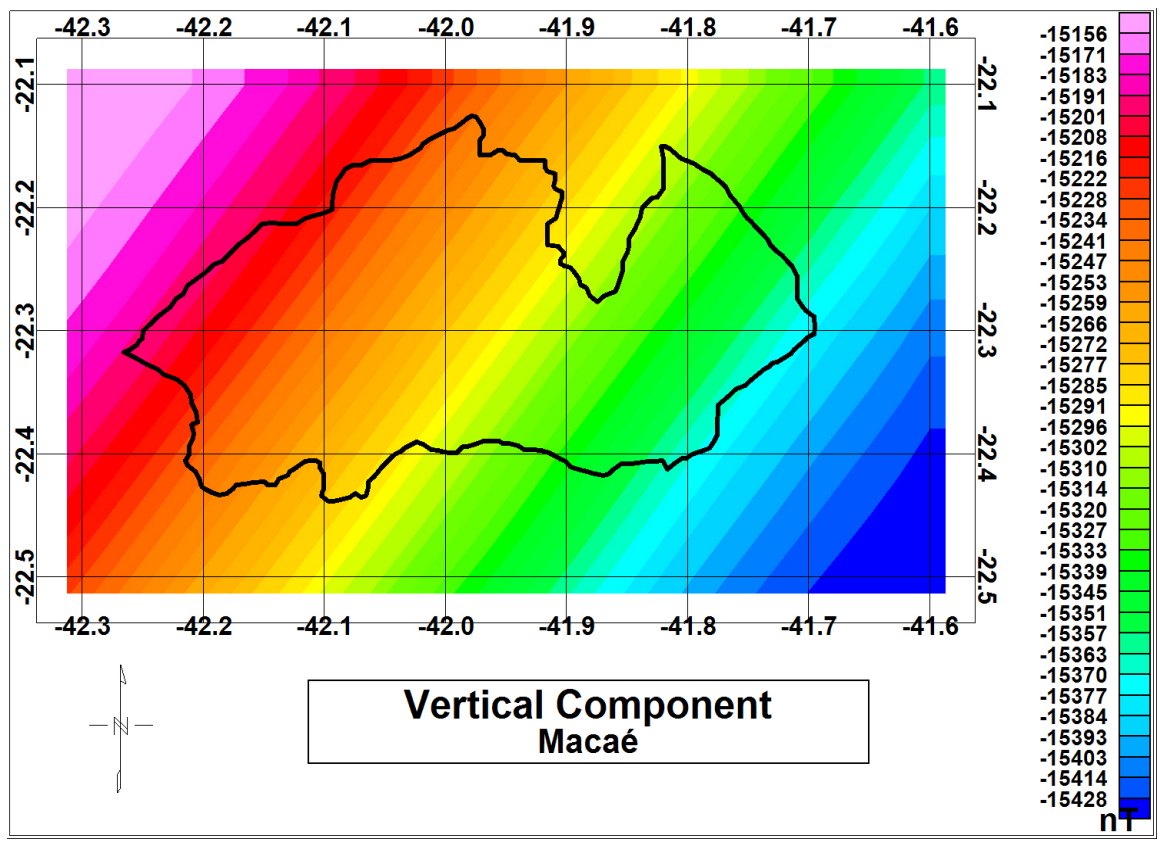

Figure 10. Z component of the magnetic field.

presented by Figure 11 and Figure 12, respectively.

As the region studied is in the southern hemisphere, negative values are expected for magnetic inclination. Thus, inclination values ranged from -41.271 degrees to -40.467 degrees, decreasing in module from southeast to northwest and varying 0.804 degrees in the region studied, which is equivalent to a variation of approximately $2 \%$.

The magnetic declination map of the region presents the greatest practical utility of this work, as it provides the difference between true north and magnetic north read in the compasses, so it can aid orientation and navigation in the region studied. Thus, declination values varied from -23.443 degrees to -23.232 degrees, decreasing in module from southwest to northeast and varying 0.211 degrees in the region studied, which is equivalent to a variation of approximately $0.9 \%$.

Through the values of the components (X, Y, Z) and Equations (3) and (4), the values of the horizontal field $(H)$ and total field $(B)$ can be calculated. The result of field interpolation (horizontal and total) is shown by Figure 13 and Figure 14, respectively.

By means of the north $(\mathrm{X})$ and east $(\mathrm{Y})$ components, the $\mathrm{H}$ component is calculated in the XY plane. The $\mathrm{H}$ component in the studied region had its values varying between $17,578 \mathrm{nT}$ and $17,768 \mathrm{nT}$, the values being increased from the southeast to the northwest of the municipality. Thus, there was an environmental variation of $190 \mathrm{nT}$ throughout the studied region, which is equivalent to approximately $1.1 \%$.

The Macaé city is currently located in a planet region that has the lowest values of magnetic field intensity, being this region called South Atlantic Anomaly 


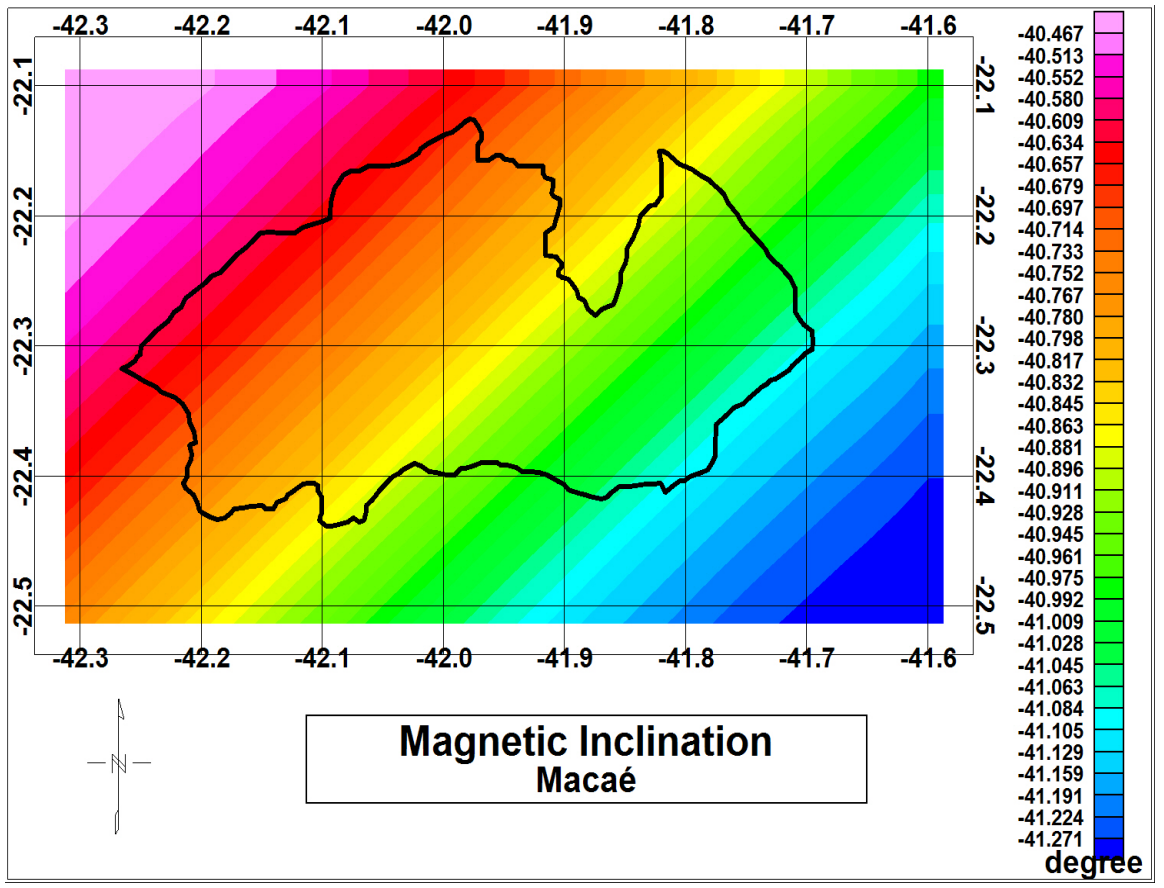

Figure 11. Magnetic inclination.

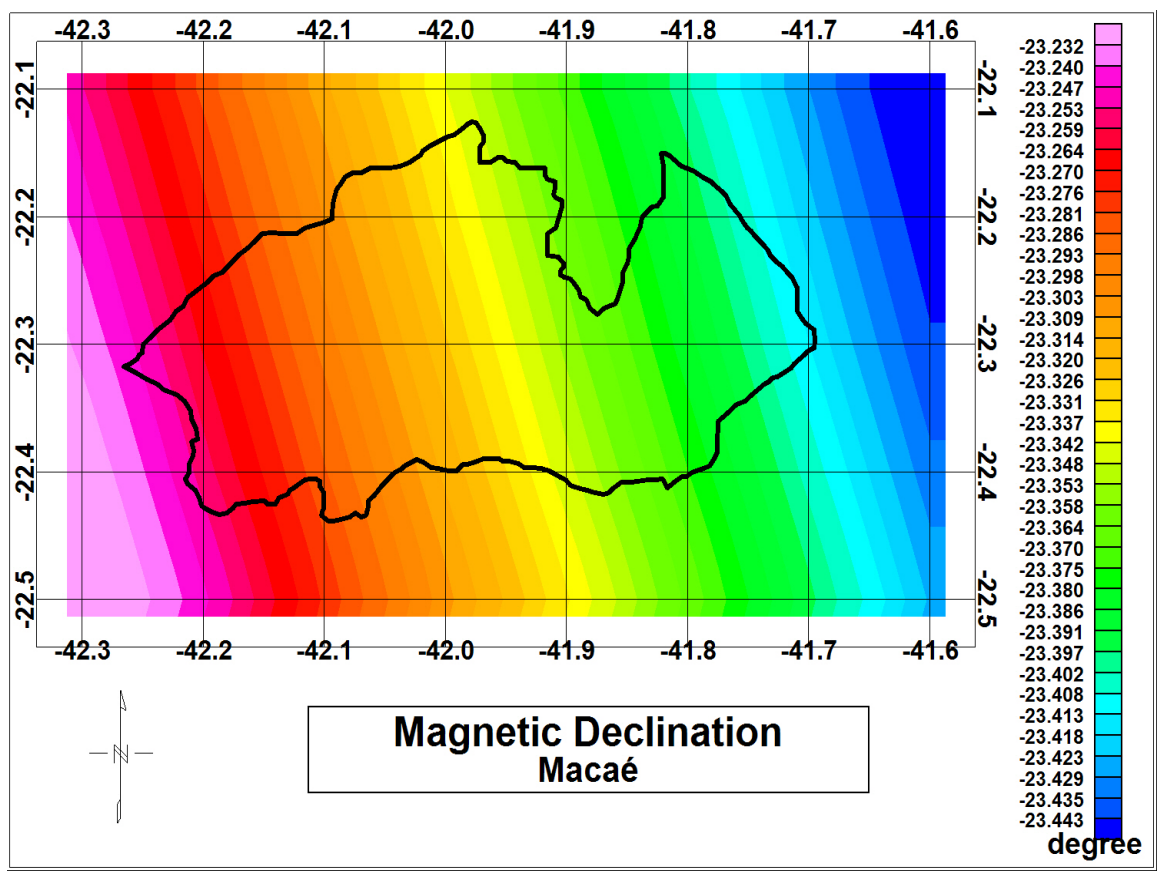

Figure 12. Magnetic declination.

(SAA). By means of the components north (X), east $(\mathrm{Y})$ and vertical $(\mathrm{Z})$, the total field $B$ is calculated. Finally, the total field $B$ in the studied region had its values varying between 23,332 $\mathrm{nT}$ and 23,410 $\mathrm{nT}$, the values being increased from the southwest to the northeast of the municipality. Thus, a $78 \mathrm{nT}$ environment variation occurred throughout the studied region, which is equivalent to approximately $0.3 \%$. 


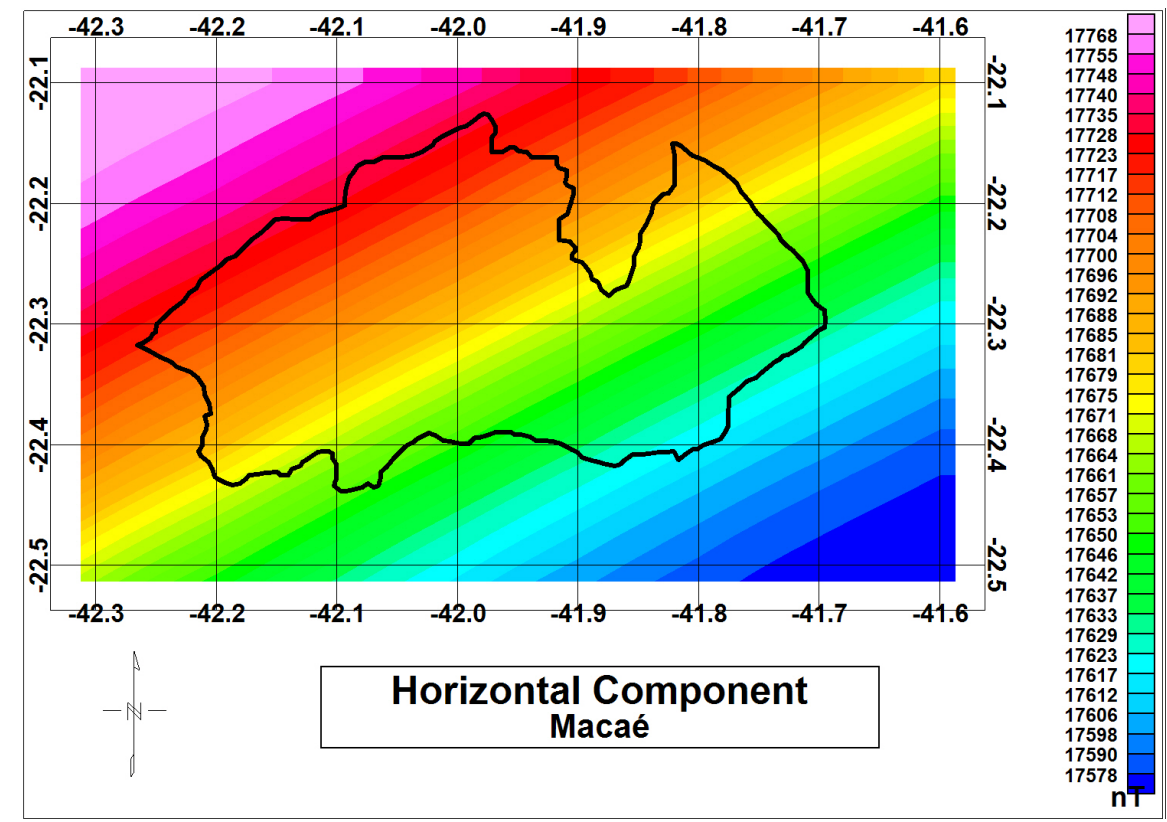

Figure 13. Horizontal component calculated from data of the $\mathrm{X}$ and $\mathrm{Y}$ components of the IGRF-12 model.

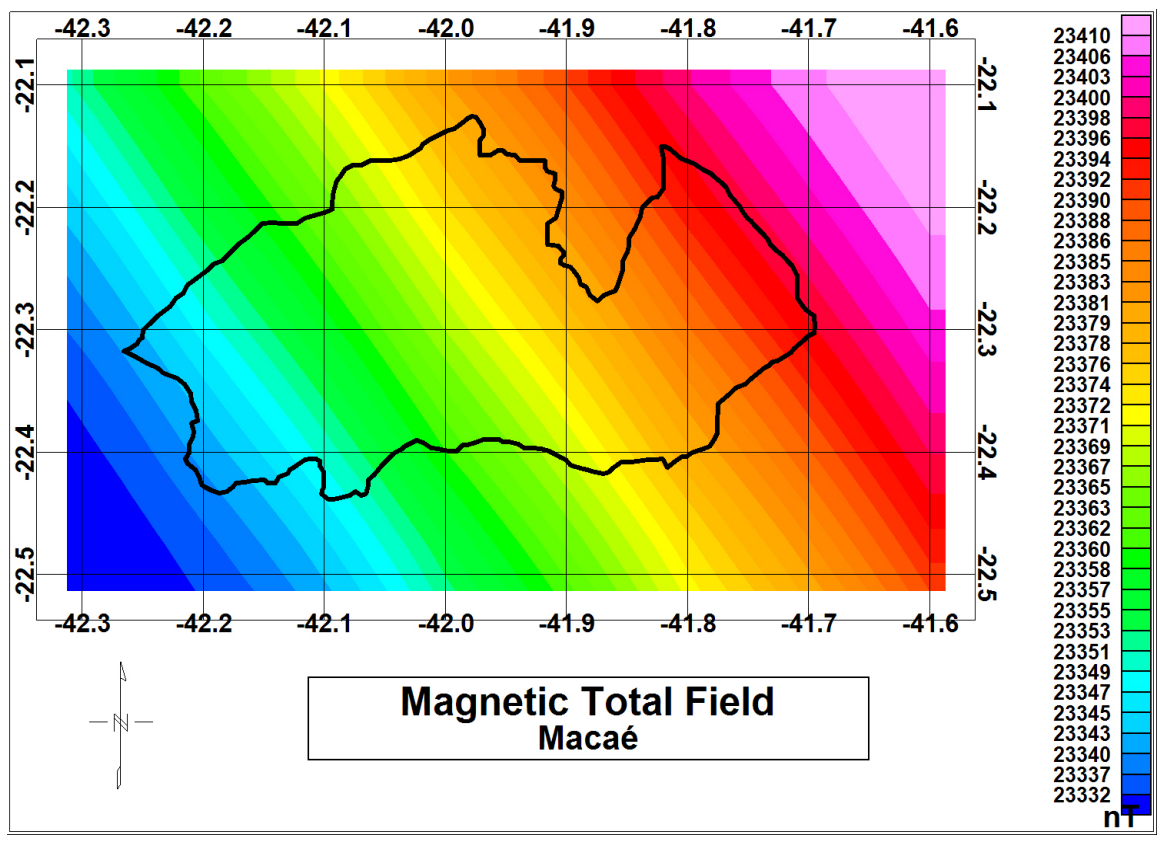

Figure 14. Magnetic Total Field calculated from data of the X, Y and Z components of the IGRF-12 model.

\section{Conclusions}

This work presents the characterization of the geomagnetic field in the municipality of Macaé using data from the IGRF-12 model for the date of February 26, 2019. Throughout the work, the characteristics of the studied area, geomagnetic field and IGRF model were described.

Component maps (X, Y, Z), angles (inclination and declination) and resulting 
(horizontal and total) were made by interpolation by minimum curvature with $1 / 4$ cells of the resolution of the data, that is, 0.25 degrees. Thus, the maps made bring as a main novelty, the detailed characterization of the geomagnetic field, showing the small variations of the magnitudes along with the municipality.

It was verified that the geomagnetic quantities had small, however, important relative variations always smaller than $2 \%$ throughout the studied area. We highlight the case of magnetic declination that varied around 0.2 degrees along the area of the municipality, which is a considerable value and capable of causing significant changes in directions by compass in the region studied.

In future studies, it is suggested the study of the temporal variation of the geomagnetic magnitudes and the study of the magnetic field of the crust of the same region should be studied, so the results can be complementary to this work.

\section{Conflicts of Interest}

The authors declare no conflicts of interest regarding the publication of this paper.

\section{References}

[1] Novak, M.A. (1999) Introdução ao Magnetismo. Segunda Escola Brasileira de Magnetismo.

[2] Miranda, J.M. (2009) Introdução ao Geomagnetismo. Instituto Dom Luiz da Universidade de Lisboa, Portugal.

[3] William, L. (2007) Fundamentals of Geophysics. Swiss Federal Institute of Technology, Zürich. https://doi.org/10.1017/CBO9780511807107

[4] Halliday, D., Resnick, R. and Walker, J. (2006) Fundamentals of Physics. Editora: LTC, Brazil.

[5] Gubbins, D. and Herrero-Bervera, E. (2007) Encyclopedia of Geomagnetism and Paleomagnetism. Springer, Berlin, Heidelberg.

https://doi.org/10.1007/978-1-4020-4423-6

[6] Lucchesi, C.F. (1998) Petróleo. Estudos Avançados, 12, 17-40. https://doi.org/10.1590/S0103-40141998000200003

[7] IBGE-Instituto Brasileiro de Geografia e Estatística (2000) O Brasil Município por Município.

[8] Santos, H.S., Gonçalves, M.E. and Gomes, A.P. (2014) Características da Radioatividade Natural do Município de Macaé. Revista de Engenharias da Faculdade Salesiana, No. 1, 11-20.

[9] Emater (2008) Espaço do Agricultor. Secretaria de Agricultura e Pecuária, RJ. Brazil. http://www.espacodoagricultor.rj.gov.br/mapa/macae.asp

[10] Sandwell, D.T., Garcia, E., Soofi, K., Wessel, P. and Smith, W.H.F. (2013) Toward 1 mGal Global Marine Gravity from CRYOSAT-2, ENVISAT and JASON-1. The Leading Edge, 32, 892-899. https://doi.org/10.1190/tle32080892.1

[11] LANDSAT (2014) Earth Science Division and ECF Information. (ESDECFI). Disponível.

[12] GILBERT, W. (1991) De Magnete. English Translation by P. Mottelay of Original 1958. Dover Publications, New York. 
[13] Kearey, P., Brooks, M. and Hill, I. (2002) An Introduction to Geophysical Exploration. Blackwell Ltd., Oxford.

[14] Lanza, R. and Meloni, A. (2006) The Earth's Magnetism, An Introduction of Geologists. Springer, Berlin’, Heidelberg.

[15] Haagmans, R., Kern, M. and Plank, G. (2008) The Earth's Magnetic Field and Environment Explorers. Presentation at RSSD Seminar, ESTEC.

[16] Blakely, R.J. (1995) Potential Theory in Gravity and Magnetic Applications. Cambridge University, Cambridge. https://doi.org/10.1017/CBO9780511549816

[17] Branco, P.M. (2015) Magnetismo da Terra. CPRM. http://www.cprm.gov.br/publique/Redes-Institucionais/Rede-de-Bibliotecas---Rede -Ametista/Canal-Escola/Magnetismo-Terrestre-2623.html

[18] Thébault, E., et al. (2015) International Geomagnetic Reference Field: The 12th Generation. Earth, Planets and Space, 67, Article ID: 79. 